\title{
Eyelid Eccrine Poroma: A Case Report and Review of Literature
}

Enrique Mencía-Gutiérrez ${ }^{1}$, Carmen Navarro-Perea ${ }^{1}$, Esperanza Gutiérrez-Díaz ${ }^{1}$, María Cámara-Jurado ${ }^{2}$ , Álvaro Bengoa-González ${ }^{1}$

1. Ophthalmology, 12 De Octubre Hospital, Complutense University, Madrid, ESP 2. Pathology, 12 De Octubre Hospital, Complutense University, Madrid, ESP

Corresponding author: Enrique Mencía-Gutiérrez, emenciag@gmail.com

\begin{abstract}
Poroma is a rare benign tumor of the epidermal sweat duct unit with predilection for the head and neck. Only six cases with eyelid location have been described in the literature (PubMed). A 34-year-old male presented with a single tumor on the left upper eyelid. It was skin-colored, nodular, solid, tender with some telangiectatic vessels, and showed no ulcerated lesion. Clinical diagnosis was basal cell carcinoma. This type of lesion can mimic a malignancy. Complete excisional biopsy revealed features consistent with eccrine poroma. After three year of follow up, no recurrence was observed. The authors reviewed all the cases reported in the literature and made a summary comparing them.
\end{abstract}

Received 06/02/2020 Review began 06/11/2020 Review ended 06/24/2020 Published 06/29/2020

๑ Copyright 2020 Mencía-Gutiérrez et al. This is an open access article distributed under the terms of the Creative Commons Attribution License CC-BY 4.0., which permits unrestricted use, distribution, and reproduction in any medium, provided the original author and source are credited.
Categories: Dermatology, Ophthalmology, Pathology

Keywords: eyelid, eccrine poroma, acrosyringium, tumor, benign, diferential diagnosis, excision, epidermal, swet duct unit, porocarcinoma

\section{Introduction}

Poromas are common benign tumors of the epidermal sweat duct unit. First described by Pinkus et al. in 1956 [1], they are subclassified as eccrine poroma, hidroacanthoma simplex, poroid hidradenoma and dermal duct tumors [2]. Poromas usually occur on the palms and soles. They rarely occur on the eyelid and should be considered in the differential diagnosis of eyelid tumors, particularly with a suspected basal cell carcinoma. This case presentation discusses the clinical and microscopic features of poroma. No apocrine differentiation has ever been observed in this location. They usually appear as solitary papule or nodule in middle-aged to elderly men and women. Our patient, in this case, is the youngest (only 34 years) among all patients that are described in the published literature. Complete primary excision and subsequent microscopic examination are advocated. The possible malignant transformation is described in the literature as porocarcinoma. We report a case of eyelid eccrine poroma and compare this to the only six cases previously described (PubMed) [3-8].

\section{Case Presentation}

A 34-year-old male presented with a single slow-growing asymptomatic tumor. It had appeared one year before on the upper left eyelid, located in the middle third of the lid, and coextending into crease and eyebrow. The lesion measured $6 \times 3 \mathrm{~mm}$ in size. It was skin-colored, nodular-regular, tender, solid, not ulcerated, with some telangiectasia vessels on the surface of the tumor. Clinical diagnosis was basal cell carcinoma (Figure 1). The patient had no other lesions on the skin. The lesion was excised under local anesthesia and with macroscopic free margins of $3 \mathrm{~mm}$. Pathologic study demonstrated a tumor with a nodular silhouette, well-demarcated on macroscopic image (Figure $2 A$ ). Microscopic examination with hematoxylin-eosin stain showed the tumor connected to overlying epidermis and extending into the papillary and reticular dermis (Figure $2 B$ ). Circumscribed lobulated growth pattern was observed, with thickened cords of tumor cells that surrounded a vascular and fibrotic stroma (Figure 2C). It was composed of small cuboidal keratinocytes with small bland nuclei (small nuclei showing uniform chromatin). Small ductal luminal (ducts) were often found (Figure 2D). Surgical margin was free. According to this description, the diagnosis was a poroma. There has been no local recurrence in a follow-up of over three years. The aesthetic result was very good. 


\section{Cureus}

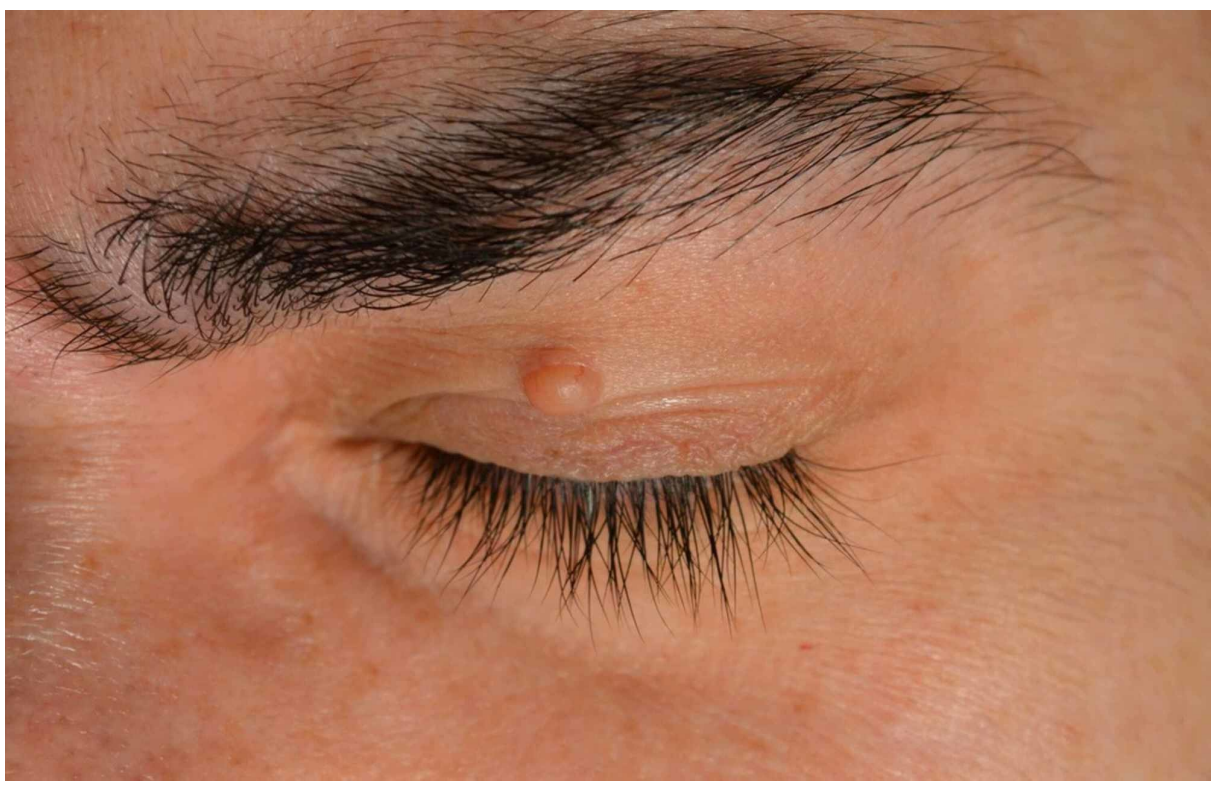

FIGURE 1: Skin-colored nodule, smooth-surface on the left upper eyelid, $6 \times 3 \mathrm{~mm}$ in size.

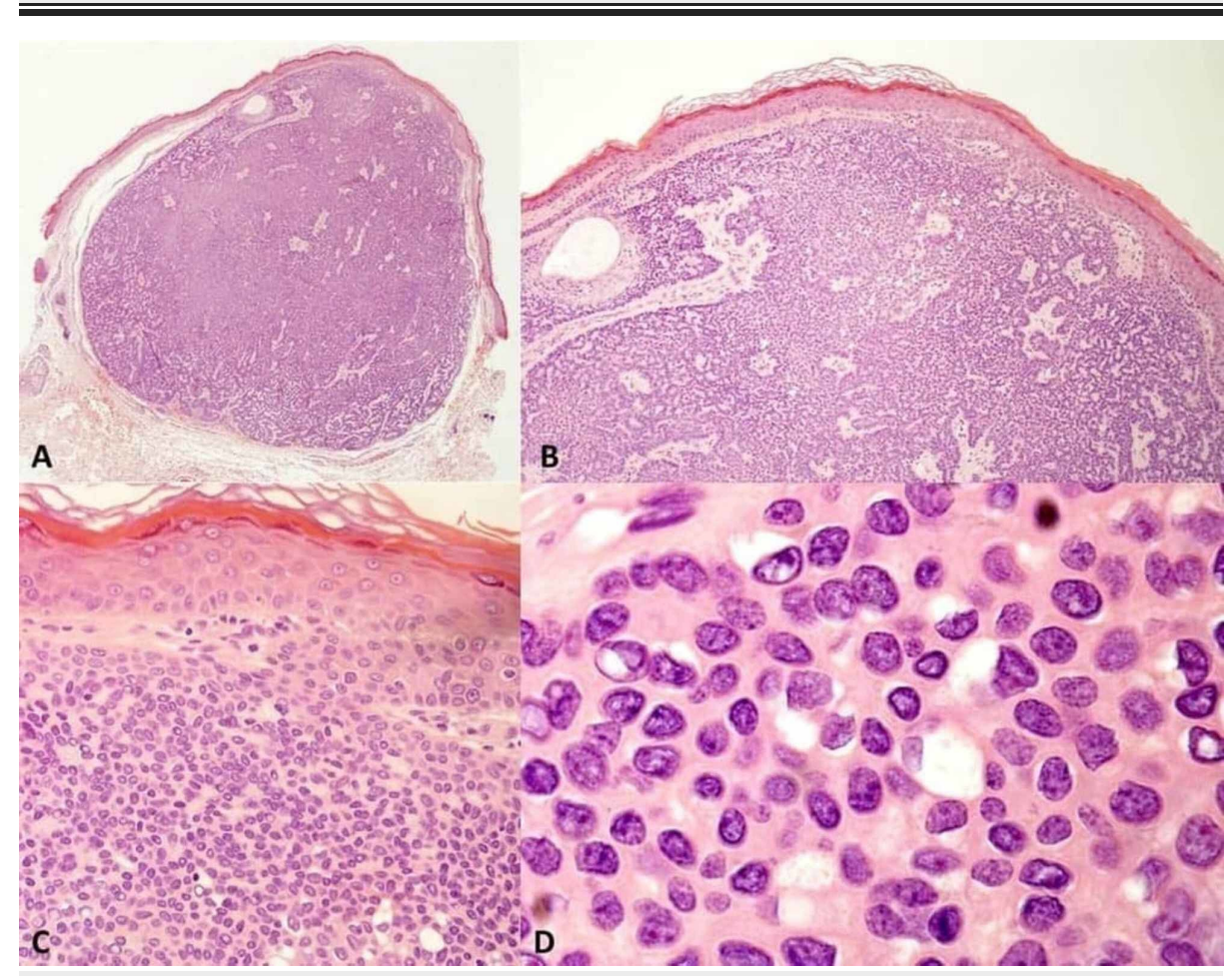

FIGURE 2: A, Well-circumscribed, totally excised tumor with lobulated growth pattern, with ticked cords of tumor cells that surround a vascular and fibrotic stroma (hematoxylin-eosin stain (H\&E), 4x). B, The tumor is connected to the overlying epidermis and extends into the papillary and reticular epidermis. Circumscribed lobulated growth pattern is observed, with thicket cords of tumor cells that surround a vascular a fibrotic stroma, (H\&E, 10x). C, The tumor is composed of small cuboidal keratinocytes with small bland nuclei (small nuclei showing a uniform chromatin) (H\&E, 40x). D, Small ductal lumina with ducts are often found (H\&E, 100x). 


\section{Discussion}

Poroma is a relatively little known skin tumor with multilineage differentiation. It is a benign cutaneous neoplasm related to the acrosyringium, and included in a group of benign adnexal neoplasm with ductal differentiation [1]. They appear preferentially on the face, palms, or soles and rarely outside of these areas [2]. Nonetheless, eccrine poroma may be found in any skin area bearing sweat glands [9]. On the eyelids, only six cases of poroma have been reported (Table1) [3-8]. Nine of the reported porocarcinomas state that they may arise de novo, or develop from a pre-existing poroma through degenerative progression [10-12].

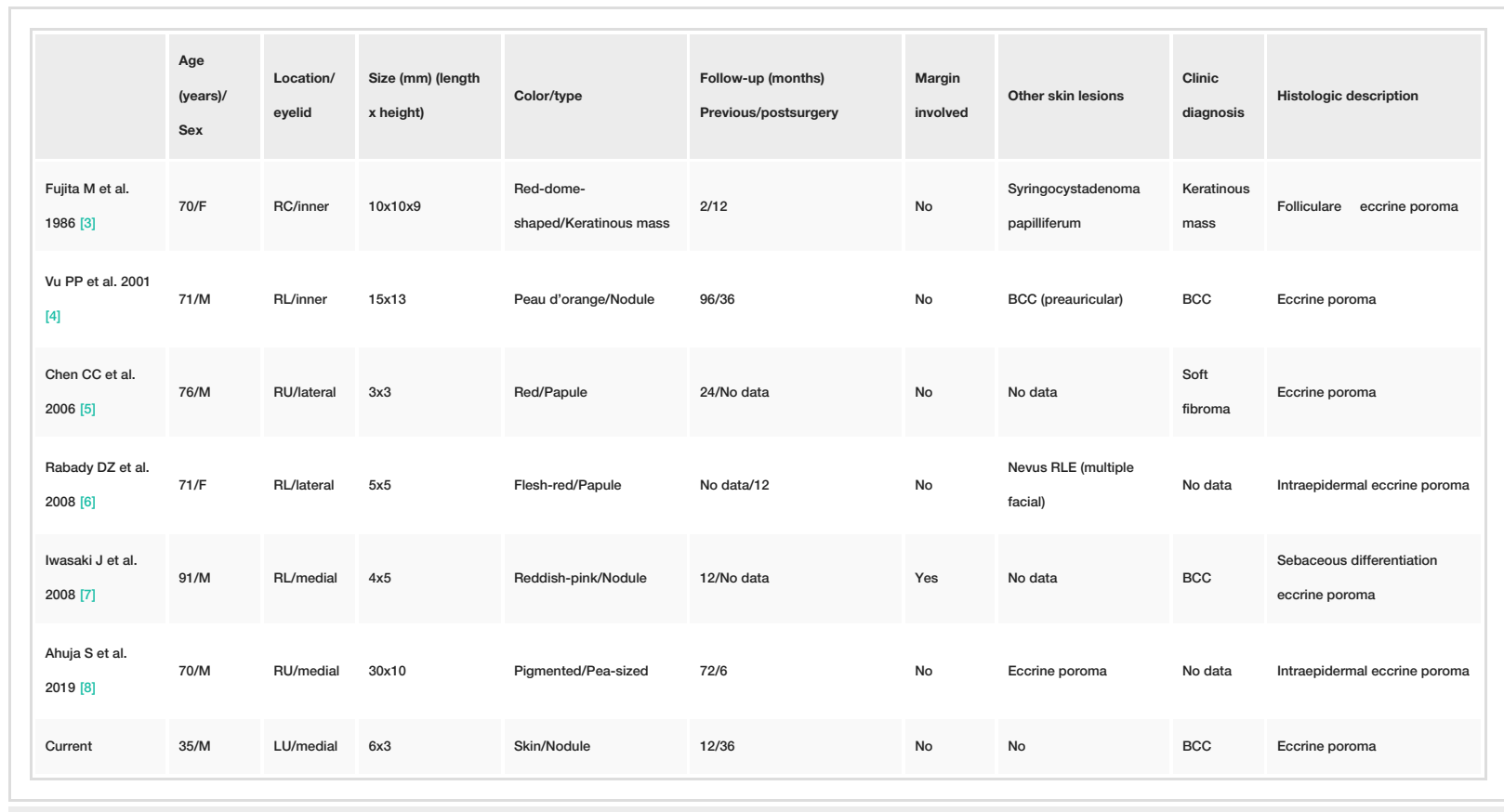

TABLE 1: Summary of cases of poroma involving the eyelids.

$\mathrm{M}=$ male, $\mathrm{F}=$ female, $\mathrm{RC}=$ right canthus, $\mathrm{RL}=$ right lower, $\mathrm{LU}=$ left upper, $\mathrm{RLE}=$ right lower eyelid, $\mathrm{BCC}=$ basal cell carcinoma

Adnexal tumors are classified based on two characteristics: benign versus malignant (the most important issue) and line of differentiation. This means determining which normal cutaneous structure the lesion most closely resembles (hair follicle, apocrine/eccrine gland, sebaceous gland). There is controversy about this subclassification and the nomenclature is still confusing. Fortunately, this is not relevant because the biological potential in all the different histological subtypes of poromas is the same. Although poromas have traditionally been thought to originate from the eccrine sweat gland, there have been cases classified as "apocrine" or "apocrine-folliculosebaceous" as well. Our case could be considered of an "eccrine type" because we cannot identify any feature suggestive of apocrine differentiation like columnar cells with holocrine decapitation secretions or "snouts" or folliculosebaceous lineage (sebaceous-like component). Carcinoembryonic antigen immunostaining can identify the presence of both eccrine and apocrine ducts and thus help in the identification. If the poroma displays more tubular foci lined by columnar cells with holocrine secretions, this may be highly suggestive of an apocrine etiology. It is thought that a poroma with sebaceous differentiation is most likely to be of folliculosebaceous-apocrine lineage [11]. Sometimes, tumor cells can show a squamoid appearance, or be clear or pigmented. Mitotic figures may be present and can be numerous in traumatized lesions [13].

Poromas affecting the head and neck are more typically of apocrine origin. On the eyelid, all cases described were eccrine [3-8]. Rare cases associated with radiation therapy and pregnancy have been described [14]. They are rarely multiple [15].

In poromas, the mean age at diagnosis was 68.3 years. Males showed a much higher incidence than females with a ratio of 15:1. In those reported on the eyelid, the mean age was 69.1 , and the proportion male to female 5:2. Our case is the youngest one at only 34 years and was a male. All the lesions were single, and varied in mean size from 0.7 to $1 \mathrm{~cm}$ in diameter; and in the eyelid, the range was 0.4 to $2 \mathrm{~cm}$ in diameter. This case is within the mean, at $0.6 \mathrm{~cm}$. Most of the lesions were asymptomatic as in the presented case. Previous evolution time was 36 months, and in the cases reported in the eyelid, it was the same. In our case, it was only one year, a possible sign of malignancy. The color of lesions varies from red to brown; in our case, it was skin-colored. None of the tumors on the eyelid had a correct preoperative diagnosis [5]. The main 
misdiagnosis was a basal cell carcinoma.

Selected differential diagnosis must be made with benign eccrine sweat gland tumors such as hidradenoma, syringoma, chondroid syringoma among others, as well as with irritated seborrheic keratosis. Differential diagnosis must also be made with a malignant eccrine sweat gland tumor as porocarcinoma and with a basal cell carcinoma, squamous cell carcinoma, sebaceous gland carcinoma (it can be difficult to differentiate clinically) and in general with other lesions of the eyelid and periocular skin.

Poroma lacks horn pseudocysts of seborrheic keratosis and clefts, peripheral palisading, and atypia nuclear of basal cell carcinoma. In contrast, a careful search for small ductal luminal or cuticles, sometimes better highlighted with immunostains for carcinoembryonic antigen or stains for periodic acid-Schiff, leads to a correct diagnosis of poroma [11].

Poroma also needs to be distinguished from its malignant counterpart, the porocarcinoma, which may arise from it or simulate features of poroma. Porocarcinomas will usually show an infiltrative growth pattern and marked atypia. It is important to know that we can find extensive necrosis, mitosis, and also epithelial atypia in benign poromas when they are mechanically irritated [11].

\section{Conclusions}

To date, there have been only six cases of eyelid poroma reported in the literature (PubMed). It is a benign neoplasm of the eccrine gland with ductal differentiation. The etiology is not clear. They are thought to differentiate towards (or originate from) the distal part of the sweat duct. They were formerly considered eccrine but may also present with apocrine differentiation (in our case, apocrine differentiation was not found). The definitive treatment of eccrine poroma consists of complete surgical excision with clear margins to avoid local recurrence. It is therefore important to consider it in the differential diagnosis of any eyelid tumor. The main problem is mistaking it with a carcinoma and performing an unnecessary extensive resection.

\section{Additional Information \\ Disclosures}

Human subjects: Consent was obtained by all participants in this study. Ethics committee 12 de Octubre Hospital, Madrid, Spain issued approval NA. Conflicts of interest: In compliance with the ICMJE uniform disclosure form, all authors declare the following: Payment/services info: All authors have declared that no financial support was received from any organization for the submitted work. Financial relationships: All authors have declared that they have no financial relationships at present or within the previous three years with any organizations that might have an interest in the submitted work. Other relationships: All authors have declared that there are no other relationships or activities that could appear to have influenced the submitted work.

\section{References}

1. Pinkus H, Rogin JR, Goldman P: Eccrine poroma: tumors exhibiting features of the epidermal sweat duct unit. AMA Arch Derm. 1956, 74:511-521. 10.1001/archderm.1956.01550110055013

2. Abenoza P, Ackerman AB: Neoplasms with eccrine differentiation. Ackermann's Histological Diagnosis of Neoplastic Skin Disease. Lea \& Febiger, Philadelphia; 1990. 15:113-185.

3. Fujita M, Kobayashi M: Syringocystadenoma papilliferum associated with poroma folliculare . J Dermatol. 1986, 13:480-482. 10.1111/j.1346-8138.1986.tb02981.x

4. Vu PP, Whitehead KJ, Sullivan TJ: Eccrine poroma of the eyelid. Clin Exp Ophthalmol. 2001, 29:253-255. 10.1046/j.1442-9071.2001.00417.x

5. Chen CC, Chang YT, Liu HN: Clinical and histological characteristics of poroid neoplasms: a study of 25 cases in Taiwan. Int J Dermatol. 2006, 45:722-727. 10.1111/j.1365-4632.2006.02741.x

6. Rabady DZ, Carlson JA, Meyer DR: Poroma of the eyelid. Ophthalmic Plast Reconstr Surg. 2008, 24:63-65. 10.1097/IOP.0b013e31816102c8

7. Iwasaki J, Yoshida Y, Yamamoto O, Tajima S: Poroma with sebaceous differentiation of the eyelid: a rare site of occurrence. Acta Derm Venereol. 2008, 88:166-167. 10.2340/00015555-0347

8. Ahuja S, Kaur A, Goel M, Raghuvanshi S, Arya A: Eccrine intraepidermal poroma of the eyelid. Indian J Ophthalmol. 2019, 67:131-132. 10.4103/ijo.IJO 54718

9. Flux K, Eckert F: Apocrine poroma: a relatively little know skin tumor with multilineage differentiation [Article in German]. Pathologe. 2014, 35:456-461. 10.1007/s00292-014-1931-1

10. Boynton JR, Markowitch W Jr: Porocarcinoma of the eyelid. Ophthalmology. 1997, 104:1626-1628. 10.1016/s0161-6420(97)30072-4

11. Sawaya JL, Khachemoune A: Poroma: a review of eccrine, apocrine, and malignant forms . Int J Dermatol. 2014, 53:1053-1061. 10.1111/ijd.12448

12. Conger JR, Palileo BM, Grob SR, Tao J, Minckler DS: Eccrine porocarcinoma: a rare tumor of the eyelid with a novel histopathological finding of free tumor cells in the tear film. Ophthalmic Plast Reconstr Surg. 2020, 36:e40-e43. 10.1097/IOP.0000000000001544

13. Cutaneous adnexal tumors. (2020). Accessed: June 1, 2020: https://www.uptodate.com/contents/cutaneousadnexal-tumors/print. 


\section{Cureus}

14. Moon J, Lee JS, Park HS, Yoon HS, Cho S: Eccrine poroma with rapid growth during pregnancy: a case report and review of the literature. Ann Dermatol. 2018, 30:222-225. 10.5021/ad.2018.30.2.222

15. Nguyen K, Kim G, Chiu M: Eccrine poromatosis following chemotherapy and radiation therapy . Dermatol Online J. 2019, 25:11. 